\title{
SISTEM PENDETEKSI KEASAMAN DAN WARNA URIN SEBAGAI INDIKASI DINI DEHIDRASI
}

\author{
Fathur Rohman K, M. Vidi Pratama, Nana Sutarna*, \\ dan Bernadeta Siti Rahayu Purwanti \\ Prodi Elektronika Industri, Jurusan Teknik Elektro, Politeknik Negeri Jakarta, \\ Jl. Prof Dr. GA. Siwabessy Kampus UI, Depok, 16425 Indonesia \\ *nana.sutarna@elektro.pnj.ac.id
}

\begin{abstract}
Dehydration is a condition of lack of body fluids because the amount of fluid that comes out is more than the amount of fluid that is entered. The impact of dehydration will be at risk for obesity and decreased concentration. Dehydration also affects the function of a person's cognitive brain abilities and memory. Acute dehydration should be avoided considering the dangers it causes to health. The simplest test for dehydration is to look at the color of urin. However, urin color can also be affected by the intake of certain foods. In this study, a urinal system equipped with a color sensor and a $\mathrm{pH}$ sensor was designed. The $\mathrm{pH}$ sensor H-101 and a TCS3200 color sensor are used in this research. The pH sensor was added to avoid urin detection errors due to urin color reading errors. The TCS3200 sensor is classified in RGB color levels (Red, Blue, Green). Urin is detected by its color level or pH acidity as input to determine the level of dehydration. The results of a person's urin detection are displayed on the LCD display. The measurement results showed that the more acidic or dominant the $R$ and $G$ color of a person's urin, the higher the dehydration level. The limit to the level of hydration of a person if the acidity of the urin has a $\mathrm{pH}<6$.
\end{abstract}

Keywords: Dehydration, pH Sensor, TCS3200, Urinal, Urin,

\begin{abstract}
ABSTRAK
Dehidrasi merupakan suatu kondisi kekurangan cairan tubuh karena jumlah cairan yang keluar lebih banyak daripada jumlah cairan yang masuk. Dampak dehidrasi akan beresiko mengalami obesitas dan penurunan konsentrasi. Dehidrasi juga mempengaruhi fungsi kemampuan kognitif otak dan memori seseorang. Dehidrasi akut harus dihindari mengingat bahaya yang ditimbulkannya bagi kesehatan. Tes paling sederhana untuk dehidrasi adalah dengan melihat warna urin. Namun warna urin juga bisa dipengaruhi oleh asupan makanan tertentu. Pada penelitian ini dirancang suatu sistem perkemihan yang dilengkapi dengan sensor warna dan sensor pH. Sensor pH H-101 dan sensor warna TCS3200 digunakan dalam penelitian ini. Sensor $\mathrm{pH}$ ditambahkan untuk menghindari kesalahan deteksi urin akibat kesalahan pembacaan warna urin. Sensor TCS3200 diklasifikasikan dalam level warna RGB (Merah, Biru, Hijau). Urin dideteksi dengan tingkat warna atau keasaman $\mathrm{pH}$ sebagai masukan untuk menentukan tingkat dehidrasi. Hasil deteksi urin seseorang ditampilkan di layar LCD. Hasil pengukuran menunjukkan bahwa semakin asam atau dominan warna $\mathrm{R}$ dan $\mathrm{G}$ urin seseorang maka semakin tinggi tingkat dehidrasinya. Batas tingkat hidrasi seseorang jika keasaman urin memiliki $\mathrm{pH}<6$.
\end{abstract}

Kata kunci: Dehidrasi, pH Sensor, TCS3200, Urinoir, Urin 


\section{PENDAHULUAN}

Artikel ini membahas tentang keasaman urin yang akan menentukan level dehidrasi. Seseorang terindikasi dehidrasi bila kekurangan cairan di dalam tubuhnya, akibat kekurangan minum atau asupan mineral. Oleh karena itu, air merupakan bagian penting dari tubuh manusia. Tubuh manusia terdiri dari 63\%-nya air, $17 \%$ lemak, $6 \%$ mineral, $1 \%$ karbohidrat dan vitamin. Seseorang yang kehilangan $\pm 20 \%$ cairan dari tubuhnya dapat menyebabkan kematian [1]. Hilangnya cairan tubuh seseorang sebagai indikasi gejala dehidrasi, dan beresiko obesitas. Dampak lain dari dehidrasi dapat menurunkan konsentrasi belajar [2]. Jumlah orang yang obesitas akibat dehidrasi sangat tinggi [2][3], namun tidak terkait dengan status gizi [1][2]. Berbeda dengan pendapat peneliti [4], dehidrasi terkait erat dengan jumlah asupan cairan. Kehilangan cairan di dalam tubuh $\geq 1 \%$ mengakibatkan fungsi otak kognitif terganggu dan daya ingat yang pendek [5]. Gejala-gejala terindikasi dehidrasi awal yaitu seseorang merasa kehausan, pusing, lemas, hingga denyut nadi meningkat [1]. Factor kelelahan akibat dehidrasi akan menurunkan tingkat konsentrasi bahkan hingga pingsan [4]. Deteksi sederhana untuk mengetahui seseorang mengalami dehidrasi adalah dari warna urin [6]. Dehidrasi dapat terindakasi dari warna urin. Warna urin juga dapat menginidikasikan penyakit seseorang. Contoh, warna urin kuning pekat kecoklatan akibat eksersi dengan empedu terindikasi masalah hati [7].

Cara mudah untuk mengetahui warna urin adalah ketika buang urin di urinoir. Tempat tersebut dapat dimanfaatkan untuk mengukur kondisi warna urin dengan menambahkan alat deteksi tertentu. Desain urinoir terkait pembuangan urin telah dibuat otomatis oleh beberapa peneliti [8][9]. Urinoirnya didesain untuk bisa menampung urin agar bisa dideteksi oleh sensor. Desain urinoir [10] dilengkapi dengan sensor warna TCS3200 dan sensor gas kadar amoniak MQ135 sebagai detector dehidrasi. Peneliti [11] mendeteksi dehidrasi dengan metode image processing pada warna urin menggunakan camera logitech G270. Data kemudian diolah dengan program python untuk mencari nilai $U$ dan $\mathrm{Y}$ sebagai penentu klasifikasi dehidrasi. Peneliti [12][13] melakukan pengukuran tingkat dehidrasi dengan memanfaatkan sensor warna, atau $\mathrm{pH}$ meter.

Menurut American Association for Clinical Chemistry, nilai rata-rata $\mathrm{pH}$ urin normal yaitu 6.0. Bila $\mathrm{pH}<6.0$ yang menandakan adanya penumpukan karbondioksi dalam darah [14]. Ini mengindikasikan adanya dehidrasi. Pengukuran
$\mathrm{pH}$ urin ada kaitannya dengan penyakit ginjal [15]. Menurut [15] pH urin normal adalah 6.5. Peneliti [13] telah membuat alat pendeteksi fungsi ginjal dengan mengukur $\mathrm{pH}$ dan warna urin. Hasil pengukurannya kemudian dibandingkan dengan hasil Analisa pakar untuk menentukan tingkat kondisi ginjal dan dehidrasi. Menurut [16], pH urin normal manusia antara 5.5 - 7.5. PH urin dibawah 5 adalah asam, sedangkan $\mathrm{pH}$ urin diatas 8.0 adalah basa.

Namun demikian, penentuan dehidarasi berdasarkan warna urin masih bisa diperdebatkan. Hal ini karena warna urin bisa juga dipengaruhi oleh asupan makanan dan obatobatan yang dikonsumsi sebelumnya [17]. Penggunaan sensor warna TCS3200 yang dilakukan oleh [18] sebagai metode deteksi warna urin masih menunjukkan kelemahan. Dimana sensor TCS3200 dalam pendeteksian warna urin masih dipengaruhi oleh intensitas cahaya. Dengan demikian sangat memungkinkan sekali akan adanya kesalahan pendeteksian warna urin.

Berdasarkan pemaparan tersebut, pada penelitian ini telah diusulkan sebuah pengukuran dehidrasi melalui deteksi keasaman urin. Pengukuran keasamannya dilakukan oleh sensor pH H-101 sedangkan deteksi warna urin dilakukan oleh sensor TCS3200. Dengan demikian kesalahan pembacaan warna urin akibat efek asupan zat warna makanan dapat dikoreksi oleh $\mathrm{pH}$ urin.

\section{METODE PENELITIAN}

Penelitian ini ditekankan pada rancang bangun urinoir untuk pengukuran keasaman urin pendeteksi dehidrasi. Sensor $\mathrm{pH}$ dan sensor warna ditempatkan pada saluran penampungan urin sebagai pengganti leher angsa. Warna urin yang terdeteksi diklasifikasikan berdasarkan komposisi RGB (Red, Green, Blue). Data dari sensor $\mathrm{pH}$ dan hasil komposisi RGB diproses dalam arduino nano Status dehidrasi kemudian ditampilkan di LCD.

Hasil akhir dari desain urinoir ditunjukkan pada Gambar 1. Dengan ukuran dimensi sebagai berikut: panjang $25 \mathrm{~cm}$, lebar $34 \mathrm{~cm}$, dan tinggi $34 \mathrm{~cm}$. 


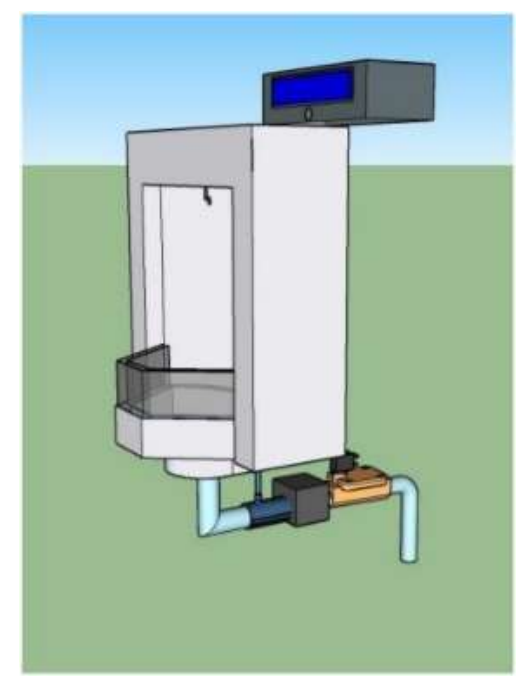

Gambar 1. Desain Urinoir

Urinoir ini juga dilengkapi dengan sensor infrared untuk menentukan jarak pengguna dengan urinoir. Hasil deteksinya digunakan untuk menutup control valve pada saluran penampungan urin. Tujuannya untuk menahan urin pada saat proses pendeteksian $\mathrm{pH}$ dan warna. Area kapasitas daya tampung urin sebesar $100 \mathrm{ml}$. Urinoir akan disiran dengan air bersih selama $8 \mathrm{~s}$ setelah sensor infrared tidak mendeteksi adanya pengguna. Pada kondisi tersebut posisi control valve terbuka untuk membuang seluruh urin dengan air bersih.

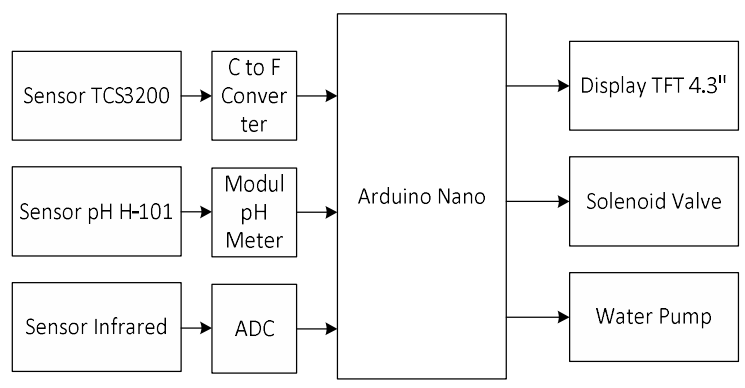

Gambar 2. Diagram Blok Sistem Pendeteksi Status Hidrasi

Blok diagram elektronik untuk sistemnya ditunjukkan pada Gambar 2. Gambar 3 adalah alur kerja system pengukuran pendeteksi keasaman urin.
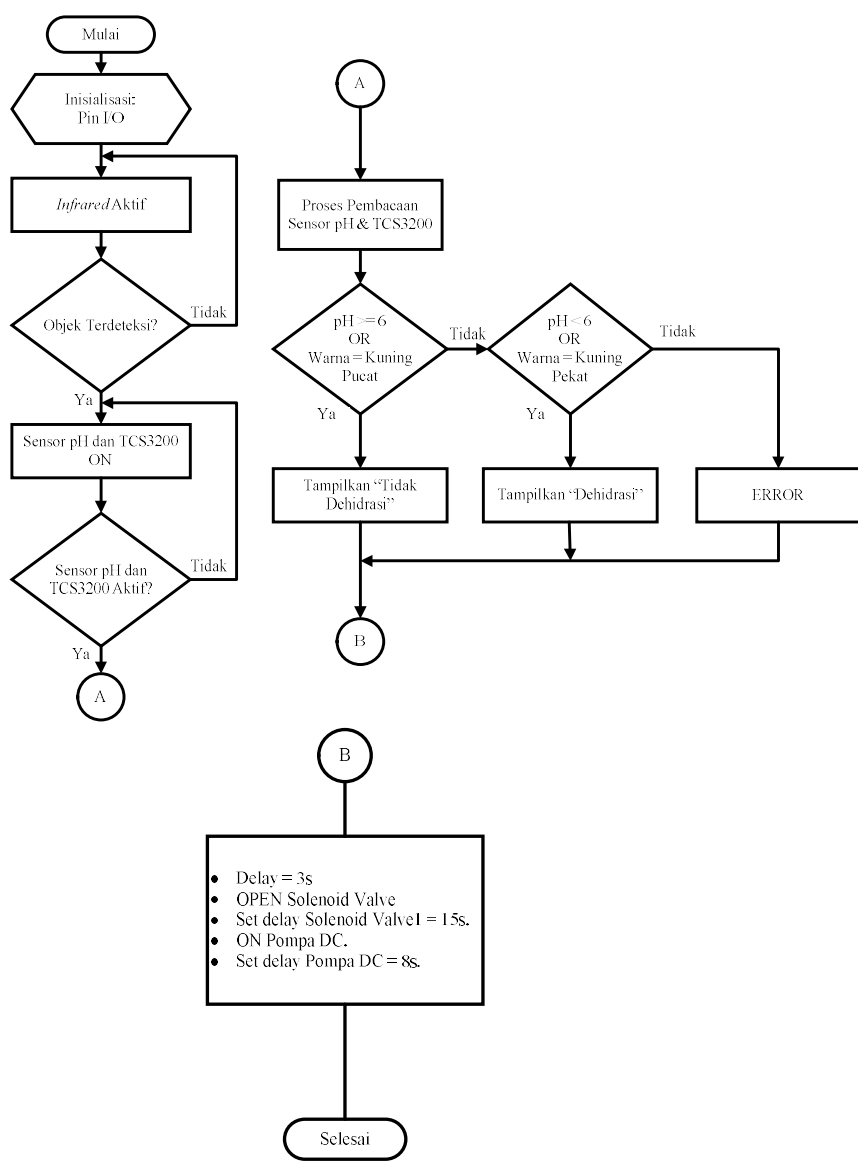

Gambar 3. Flowchart Sistem Urinoir

\section{HASIL DAN PEMBAHASAN}

\subsection{Uji Validasi Sensor pH H-101}

Sebelum pengukuran keasaman urin dilakukan, sensor $\mathrm{pH} \mathrm{H-101} \mathrm{divalidasi} \mathrm{terlebih}$ dahulu. Metodenya dengan membandingkan antara hasil pengukuran sensor $\mathrm{pH} \mathrm{H}-101$ dengan $\mathrm{pH}$ meter. Hasilnya menunjukkan bahwa tingkat error untuk sensor $\mathrm{H}-101$ terhadap $\mathrm{pH}$ meter selisihnya adalah 0.1 digit. Tabel 1 adalah hasil pengukuran sensor $\mathrm{pH} \mathrm{H}-101$ dan $\mathrm{pH}$ meter. Sedang Gambar 4 adalah grapik perbandingan antara keduanya yaitu $\mathrm{pH} \mathrm{H}-101 \mathrm{H}$ meter $\mathrm{H}$ $101 \mathrm{H}$.

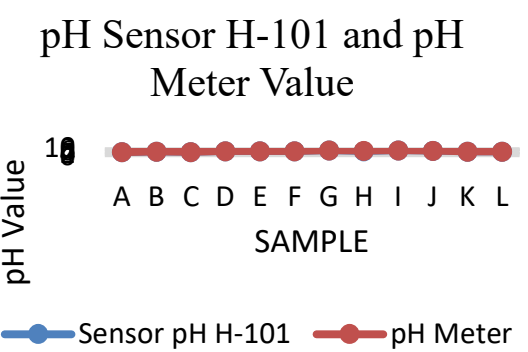

Gambar 4. Grafik Data Sensor dan Alat Ukur 


\section{Sistem Pendeteksi Keasaman dan Warna Urin}

Tabel 1. Pengujian Pendeteksian Sensor pH H101

\begin{tabular}{|c|c|c|c|}
\hline \multirow[b]{2}{*}{ Sampel } & \multicolumn{2}{|c|}{ Hasil Pendeteksian } & \multirow{2}{*}{$\begin{array}{c}\text { Persentase } \\
\text { Error } \\
(\%)\end{array}$} \\
\hline & $\begin{array}{c}\text { Sensor } \\
\mathrm{pH} \mathrm{H}- \\
101\end{array}$ & $\begin{array}{c}\mathrm{pH} \\
\text { Meter }\end{array}$ & \\
\hline A & 5,3 & 5,3 & 0 \\
\hline B & 6,0 & 6,0 & 0 \\
\hline $\mathrm{C}$ & 5,5 & 5,5 & 0 \\
\hline D & 6,8 & 6,8 & 0 \\
\hline E & 6,4 & 6,3 & 1,58 \\
\hline $\mathrm{F}$ & 6,3 & 6,3 & 0 \\
\hline G & 7,5 & 7,6 & $-1,31$ \\
\hline $\mathrm{H}$ & 6,8 & 6,9 & $-1,44$ \\
\hline I & 7,8 & 7,9 & $-1,26$ \\
\hline $\mathrm{J}$ & 7,0 & 7,1 & $-1,40$ \\
\hline K & 6,0 & 6,0 & 0 \\
\hline $\mathrm{L}$ & 6,1 & 6,2 & -1.61 \\
\hline
\end{tabular}

\subsection{Pengukuran Keasaman dan warna Urin}

Pengukuran tingkat keasaman urin dilakukan di tempat saluran pembuangan urin seperti ditunjukkan pada Gambar 1. Sensor $\mathrm{pH}$ $\mathrm{H}-101$ dan $\mathrm{pH}$ meter keduanya terendam dalam urin. Sedang sensor TCS3200 difokuskan pada urin untuk mendeteksi warna. Warna urin hasil deteksi sudah dinyatakan dalam satuan RGB. Jumlah sample yang digunakan dalam riset ini sebanyak 12. Sample-sample tersebut diberil label A - L. Hasil pengukuran sensor pH H-101 dan RGB ditunjukan pada Tabel 2.

\subsection{Pengujian Pendeteksian Hidrasi}

Penentuan status urin dehidrasi, dehidrasi ringan dan dehidrasi berat mengacu ke metode [13]. Dari 12 sample yang diuji, hanya sample A yang mengalami dehidrasi berat dengan nilai $\mathrm{pH}<5.5$. Sample lainnya mengalami dehidrasi ringan dengan nilai $5,5 \leq \mathrm{pH} \leq 7,5$, kecuali sample I. Sample urin tersebut tidak mengalami dehidrasi karena $\mathrm{pH}>7,5$.

Pada riset ini ada kasus khusus yang menarik yaitu untuk sample B dan K. Nilai RGB nya berbeda namun nilai $\mathrm{pH}$ nya sama. Hal ini kemungkinan disebabkan oleh pengaruh asupan makanan yang dikonsumsi. Dimana sensor TCS3200 mendeteksi warna yang berbeda yang ditunjukkan oleh nilai RGB.

Tabel 2. Pengujian Pendeteksian Hidrasi

\begin{tabular}{cccccc}
\hline \multirow{2}{*}{ Sampel } & \multicolumn{6}{c}{ Sensor TCS3200 } & \multicolumn{2}{c}{ Sensor } \\
& R & G & B & pH & Status \\
\hline A & 207 & 79 & 0 & 5,3 & $\begin{array}{c}\text { Dehidrasi } \\
\text { berat }\end{array}$
\end{tabular}

\begin{tabular}{|c|c|c|c|c|c|}
\hline B & 231 & 99 & 0 & 6,0 & $\begin{array}{c}\text { Dehidrasi } \\
\text { Ringan }\end{array}$ \\
\hline $\mathrm{C}$ & 207 & 59 & 0 & 5,5 & $\begin{array}{l}\text { Dehidrasi } \\
\text { ringan }\end{array}$ \\
\hline D & 219 & 40 & 0 & 6,8 & $\begin{array}{l}\text { Dehidrasi } \\
\text { ringan }\end{array}$ \\
\hline E & 219 & 79 & 0 & 6,4 & $\begin{array}{c}\text { Dehidrasi } \\
\text { ringan }\end{array}$ \\
\hline $\mathrm{F}$ & 231 & 99 & 0 & 6,3 & $\begin{array}{c}\text { Dehidrasi } \\
\text { ringan }\end{array}$ \\
\hline G & 195 & 40 & 0 & 7,5 & $\begin{array}{c}\text { Dehidrasi } \\
\text { ringan }\end{array}$ \\
\hline $\mathrm{H}$ & 233 & 174 & 6 & 6,8 & $\begin{array}{c}\text { Dehidrasi } \\
\text { ringan }\end{array}$ \\
\hline I & 228 & 158 & 30 & 7,8 & $\begin{array}{c}\text { Tidak } \\
\text { Dehidrasi }\end{array}$ \\
\hline $\mathrm{J}$ & 255 & 215 & 60 & 7,0 & $\begin{array}{c}\text { Tidak } \\
\text { Dehidrasi }\end{array}$ \\
\hline K & 255 & 235 & 77 & 6,0 & $\begin{array}{l}\text { Dehidrasi } \\
\text { ringan }\end{array}$ \\
\hline L & 255 & 255 & 135 & 6,1 & $\begin{array}{c}\text { Dehidrasi } \\
\text { ringan }\end{array}$ \\
\hline
\end{tabular}

\section{KESIMPULAN}

Berdasarkan hasil pengukuran validasi terhadap sensor $\mathrm{pH}$ yang digunakan, menunjukan bahwa urinoir pengukur keasaman urin yang sudah dibuat berfungsi dengan baik, tingkat error kesalahan pembacaannya sebesar 0.1 . Deteksi status dehidrasi terhadap tingkat keasaman urin dari sample menunjukkan ada tiga level yaitu dehidrasi berat, dehidrasi ringan dan tidak dehidrasi. Namun demikian, alat ini masih mengalami kekurangan dalam hal pengidentifikasian warna dan hanya disajikan dalam satuan nilai-nilai RGB. Dengan demikian pendeteksian status dehidrasi dengan pengukuran nilai $\mathrm{pH}$ lebih akurat dibandingkan dengan sensor warna. Kemampuan system urinoir yang sudah dibuat ini dalam kemampuan pembacaan terhadap status dehidrasi sebesaar $<$ 30 detik.

\section{DAFTAR PUSTAKA}

[1] Merita, Aisah, S. Aulia, "Status gizi dan aktivitas fisik dengan status hidrasi pada remaja di sma negeri 5 kota jambi," Jurnal Ilmu Kesehatan Masyarakat, vol. 9, no. 30, pp. 207-215, 2018.

[2] A. Buanasita, Andriyanto, I. Sulistyowti, "Perbedaan tingkat konsumsi energi, lemak, cairan, dan status hidrasi mahasiswa obesitas dan non obesitas," Indonesian Journal of human Nutrition, vol. 2, no. 1, pp. 11-22, 2015.

[3] D. Y. Fitranti, F. F. Dieny, B. Panunggal, V. sukmasari, and g. nugrahani, "Kecenderungan dehidrasi pada remaja 
obesitas," Jurnal Gizi Indonesia, vol. 7, no. 1, pp. 43-48, 2018.

[4] N. A. Sari dan T. S. Nindya, "Hubungan asupan cairan, status gizi dengan status hidrasi pada pekerja di bengkel divisi general," media gizi indonesia, vol.12, no. 1, pp. 47-53, 2017.

[5] M. Bahrudin, A. B. Nafara, "Hubungan dehidrasi terhadap memori segera/atensi," Jurnal Saintika Medika, vol. 15, no. 1, pp. 12-24, 2019.

[6] D. Wahiddin, J. Indra, "Klasifikasi kadar hidrasi tubuh berdasarkan warna urine dengan metode ekstraksi fitur warna dan euclidean distance," Jurnal Ilmu Komputer dan Teknologi Informasi, vol. 5, no. 1, pp. 16-20, 2020.

[7] Y. Noor, S. Ulvie, H. S. Kusuma, dan R. agusty, "Identifikasi tingkat konsumsi air dan status dehidrasi atlet pencak silat tapak suci putra muhammadiyah semarang," Jurnal media ilmu keolahragaan indonesia, vol. 7, no. 2, 2017.

[8] F. Adilia, A. Rakhmatsyah, A. G. Putrada, "Implementasi toilet pintar berbasis mikrokontroler implementation of smart toilet based on microcontroller," $E$ proceeding of Egineering, 2016, vol. 3, no. 3.

[9] E. Prastika, A. Hadi, "Toilet berdiri otomatis sensor PR (passive infrared) dan sensor temperature," Seminar Nasional Industri Dan Teknologi (SNIT), 2019, pp. 365-373.

[10] R. Z. Amani, R. Maulana, D. Syauqy, "Sistem pendeteksi dehidrasi berdasarkan warna dan kadar amonia pada urin berbasis sensor TCS3200 dan mq135 dengan metode naive bayes," Jurnal Pengembangan Teknomologi Informasi Dan Ilmu Komputer, vol. 1, no. 5, pp. 436444, 2017.

[11] I. Mudzakir, R. Alfita, M. Ulum, "Rancang bangun smart urinoir untuk mendeteksi status dehidrasi berbasis image processing dengan metode jaringan syaraf tiruan perceptron," JEECOM, 2020, vol. 2, no. 1, pp. 1-7.

[12] D. D. Damayanti, H. G. Ariswati, I D. G. Wisana. H. winarno, "automatic dehydration level detection devices," IJEEMI, 2020, vol. 2, no. 2, pp. 87-94.

[13] M. I. Febriyansyah, A. Yudhana, A. Ma'arif, "Urinoir analyzer: Alat pintar pendeteksi kelainan pada fungsi ginjal dengan analisis kadar $\mathrm{pH}$ dan warna pada urine," Jurnal Mobile and Forensics, vol. 2, no. 1, pp. 32-40, 2020.

[14] Shafira, F. M. Syahidah, dkk, "Perbedaan pengaruh air alkali dengan air mineral terhadap status hidrasi dan ph urin pada mahasiswa fakultas farmasi universitas padjadjaran," Farmaka, vol. 17, pp. 15-21, 2019.

[15] A. Pathya, H. Harun, "Asidosis tubular renal distal," jurnal human care, vol. 5, no. 1, pp. 265-269, 2020.

[16] Verdiansyah, "Pemeriksaan fungsi ginjal," Cermin Dunia Kedokteran, vol. 43, no. 2, pp. 148-154, 2016.

[17] R. I. Ramadhan, C. Rismayanthi, "Hubungan antara status hidrasi serta konsumsi cairan pada atlet bola basket," Medikora, vol. 15, no, 1, pp. 53-69, 2016.

[18] D. C. Pribadi, Hudiono, Waluyo, "Rancang bangun sistem monitoring tingkat dehidrasi berdasarkan warna urin menggunakan metode fuzzy logic," Jurnal Jartel, Vo./ 7, no. 2, pp. 50-55, 2018. 